study of the toxic effect of methyl mercury on sperm motility. $f$ Androl 1986;7:11-5.

25 Ford WCL. The mode of action of 6-chloro-6-deoxysugars as antifertility agents in the male. In: Jeffcoate SL, Sandler M, eds. Progress towards a male contraceptive. Chichester: Wiley, 1982:159-84.

26 Mitchinson MJ, Sherman KP, Stainer-Smith AM. Brown patches in the epididymis. I Path 1975;115:57-62.

27 Logan WPD. Mortality from pink disease in 1923-47. Lancet 1949;i:608-9.
28 Colver T. Pink disease and mercury in Sheffield, 1947-1955. BMf 1956;i: 897-908.

29 Holzel A, James T. Mercury and pink disease. Lancet 1952;i:441-3.

29 Holzel A, James T. Mercury and pink disease. Lancet 1952;i:441-3.

31 Kew J, Morris C, Aihie A, Fysh R, Jones S, Brooks D. Arsenic and mercury intoxication due to Indian ethnic remedies. BMf 1993;306:506-7.

32 Chamberlain $\mathrm{J}$, Quillian WW. Acrodynia-a long term study of 62 cases. Clin Pediatrics 1963;2:439-43.

\title{
Multicentre randomised double bind crossover trial on contamination of conventional ties and bow ties in routine obstetric and gynaecological practice
}

\author{
Marinko M Biljan, Charles A Hart, Deborah Sunderland, Paul R Manasse, Charles R Kingsland
}

\section{Abstract}

Objective-To assess level of contamination of neckwear worn by gynaecologists and obstetricians during routine working week.

Design-Multicentre randomised double blind crossover trial. Participants wore the same conventional ties for three days in one week and bow ties for the same period in second week.

Setting-Two teaching and three district general hospitals in the midlands, Wales, and north England. Subjects-15 registrars and senior registrars.

Interventions-A swab soaked in sterile saline was taken from specific area on ties at end of first and third working days and sent in transport medium for culture on chocolatised blood and MacConkey agar for 48 hours.

Main outcome measures-Level of bacteriological growth assessed semiquantitatively ( 0 for no contamination; +++ for heavy contamination) after swabs had been cultured. At end of study the participants completed a questionnaire to assess their attitude toward wearing different types of necktie.

Results -12 doctors $(80 \%)$ completed the study. Although bow ties were significantly less contaminated at end of first working day $(z=-2 \cdot 354, p=0.019)$, this difference was not maintained; there was no difference in level of contamination on third day. Level of contamination did not increase between first and third day of wearing the same garment. One of the 10 doctors who returned the questionnaire found the bow tie very uncomfortable. All participants would consider wearing a bow tie if it proved to be less contaminated than a conventional tie.

Conclusions-Although a significant difference in contamination was established between conventional and bow ties on first day of study, this difference was not confirmed on third day and there is unlikely to be any real association between tie type and bacterial contamination. Because of its negative image and difficulty to tie, the bow tie will probably remain a minority fashion.

Department of Medical Microbiology, University of Liverpool

Charles A Hart, professor of medical microbiology

Deborah Sunderland, technician

Correspondence and reprint requests to:

DrMM Biljan,

IVF Unit, Department of Obstetrics and Gynaecology, Royal Liverpool University

Hospital, Liverpool L7 8XP.

BMF 1993;307:1582-4

\section{Subjects and methods}

Doctors from two teaching and three district general hospitals in the midlands, Wales, and north England were recruited to the study. The participants were given a new conventional tie and bow tie together with illustrated instructions on how to tie them. The participants wore one tie for three days in one week, and the other tie for the same period in the second week: subjects were randomised by means of sealed opaque envelopes to wear either the bow tie or the conventional tie first.

A swab soaked in sterile saline was taken by the participants from the tip of the ties-an area with a radius of $2 \mathrm{~cm}$ on the conventional tie (obtuse angle) and $2 \mathrm{~cm}$ on the bow tie (acute angle) at the end of the first and third working day and sent in the transport medium for assessment of bacteriological growth. All the swabs were analysed by one of us (DS). The level of contamination was assessed with a semiquantitative system (from 0 for no contamination to +++ for heavy contamination) after the swabs had been cultured on chocolatised blood and MacConkey agar aerobically at $37^{\circ} \mathrm{C}$ for 48 hours.

At the end of the study the participants completed a questionnaire to assess their attitude towards wearing the different types of necktie: the participants were asked about their usual neckwear, their habit of wearing white coats, whether they felt comfortable wearing a conventional tie or bow tie, which type of neckwear they thought patients and members of staff preferred them to wear, and if they would consider wearing an alternative tie if the study showed it to be less contaminated.

\section{STATISTICAL ANALYSIS}

The data were analysed in two ways. Firstly, the degree and type of bacterial growth were ignored, and ties were simply classified according to whether there was evidence of contamination. McNemar's test was used to make comparisons (bow tie $v$ conventional tie on first day; bow tie $v$ conventional tie on third day; bow tie, first day $v$ third day; and conventional tie, first day $v$ third day). The comparisons were repeated with a change in the classification so that a score of 0 or + was counted as no contamination while a score of ++ or +++ was counted as contamination. Although this method takes account of the pairing in the study design, it does not make use of the degree of growth identified.

The second method of analysis used was to compare, in pairs, the total number of positives in the four categories (first day and third day for bow tie and conventional tie) with the Wilcoxon signed ranking test for matched pairs. The total for each doctor for each of the four categories was calculated by simply summing the score across all six combinations of media type and bacteria type. A conservative significance 


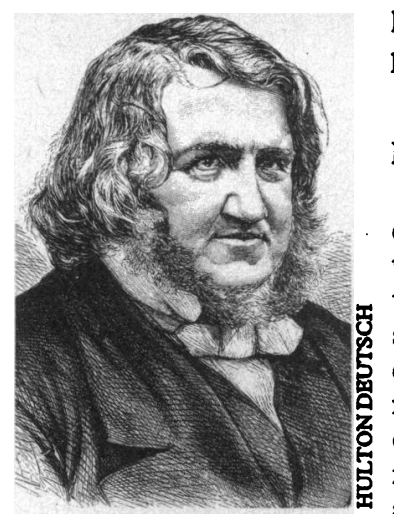

level of $\alpha=0.02$ was used because of the statistical tests performed.

\section{Results}

Twelve doctors $(80 \%)$ completed the study. One doctor kept the conventional tie and bow tie but failed to return any swabs, and two doctors returned three of the four requested swabs. A total of 54 swabs was analysed, including the six swabs from the doctors who did not return all four swabs. These six swabs showed no significant difference in contamination from the others and were excluded from the study. The remaining 48 swabs from 12 doctors were used for statistical analysis. Bacteria were present on seven bow ties on the first day of the study and on six on the third day whereas bacteria were detected on 10 conventional ties on the first day and on six on the third day of the study. The median (range) value of contamination for bow ties was $1(0-3)$ on the first day of the study and $0(0-6)$ on the third day. For conventional ties the contamination value was $2.5(0-3)$ on the first day and $0.5(0-3)$ on the third day. There was no significant order effect in wearing a bow tie for the first or second week of the trial. Alcaligenes spp were found in 16 samples, coagulase negative staphylococci in nine samples, a mixture of Alcaligenes spp and coagulase negative staphylococci in four samples, and a mixture of Enterococcus faecalis and Alcaligenes spp in one sample. None of the bacteria found contaminating these ties was potentially highly pathogenic.

With classification of ties and McNemar's test no significant differences in the level of contamination were found. Paired comparison of ties showed a significantly higher level of contamination on conventional ties on the first day $(z=-2.354, \mathrm{p}=0.019)$. Neither statistical method showed a significant increase in the contamination level between the first and third day of wearing the same tie.

The answers to the questionnaire revealed that nine doctors wore white coats all the time and three wore Tु them only occasionally. Ten doctors usually wore conventional ties and two wore both conventional and bow ties. None of the participants wore a tie pin. Nine doctors felt very comfortable wearing a conventional tie, and three felt comfortable. Five felt very comfortable wearing a bow tie, four felt comfortable, and three felt uncomfortable. Nine doctors thought that patients had no preferences regarding their doctor's choice of neckwear; two thought that patients preferred conventional ties and one that patients preferred bow ties. Eight participants thought that other medical staff preferred to see them wearing a conventional tie and

Ties through the centuries (top to bottom): Fames Young Simpson and stock; Leopold Auenbrugger's Steinkirk; cravat of William Smellie three thought that their colleagues preferred bow ties. All participants would consider wearing a bow tie if it proved to be less contaminated than a conventional tie.

\section{Discussion}

Since the establishment of the Protestant ethic in the seventeenth century the clothing of doctors, like many other professionals, has been confined to monotonous black sobriety, the dullness of which was interrupted only by white neckwear and cuffs. ${ }^{2}$ This long lasting fashion is probably best illustrated in Rembrandt's famous Anatomy Lesson, which portray $\mathrm{Dr}$ Nicholas Turp, professor of anatomy at Leiden University, with his pupils-all are wearing plain black clothes and a beautiful selection of immaculate white collars. ${ }^{3}$ As fashions have changed doctors have kept their traditional elegant and respectable black clothing, adding a touch of individuality through the neckwear. The stock worn by James Young Simpson, ${ }^{3}$ the Steinkirk of Leopold Auenbrugger, ${ }^{4}$ the cravat of William Smellie, ${ }^{3}$ the neckerchief of John Yelloly, ${ }^{5}$ the bow tie of Ignaz Semmelweis, ${ }^{3}$ and the beautiful lace cravat of John Radcliffe ${ }^{3}$ say more about the individualities of these doctors than about the fashion of their time.

In the search for more practical neckwear at the turn of the century the bow tie enjoyed a prolonged period of popularity. Reviewing the blue and white spotted bow tie in 1900, the Tailor and Cutter, a fashion magazine of the era, thought that on balance it was the necktie in which the average Englishman looked best - blue and white, in spots and stripes. ${ }^{6}$ Combinations of red and green were thought also never to go out of fashion. The increased use of the low collar and open suit since 1930 has seen the bow tie gradually being replaced as the main neckwear by the simple to tie "four in hand" (conventional) tie.

Throughout the history of medicine doctors have only sporadically shown any interest in the possible implications of their personal hygiene and clothing on the health of their patients. Although in Roman times Galen pointed out the importance of cleanliness to successful medical practice, ${ }^{2}$ this idea was largely ignored up to the middle of the nineteenth century. In 1853 surgeons at University College Hospital in London operated in their oldest frock coats, stained with decades of dirt and blood. ${ }^{2}$ In his oration on Lister in 1913 Sir Rickman Godlee declared: "The nurses are nice and bright and clean, and so is the butterfly cap of the nun-like sister, but one cannot be sure that the same is true for her black flannel gown looped around by a rope girdle at her waists. This might be as dirty as the surgeon's."

First to point out the importance of doctors' hygiene, the Hungarian obstetrician Ignatz Semmelweis was not only dismissed from both Vienna's General Hospital and Budapest's St Rochus Hospital but was also admitted to an asylum for the insane, where he died from septicaemia. ${ }^{8}$ It took the authority and determination of Joseph Lister, a Quaker, to initiate changes in hygiene and the clothing habits of the medical profession. He began to insist, among other measures, on sterilised clothes for operating theatres instead of frock coats and aprons straight off the ward or the street. Today, although Lister's ideas are fully implemented in operating theatres, delivery suites tend to adopt much more relaxed policies, following the idea that delivery is a natural process and that the labour ward and medical staff working there should resemble as closely as possible the home environment. Fifteen per cent of the doctors in our study chose not to wear a white coat on the labour ward, and none used a pin to fix a long tie. As a result of this it is likely that such ties get stained in amniotic 


\section{Sartorial implications}

- The decline in the sartorial elegance often associated with the medical profession particularly in the field of obstetrics and gynaecology, seems to have accelerated over the past generation

- The wearing of bow ties has decreased

- The results of the study suggest a possible lower contamination of bow ties

- In spite of the results of this study, because of its peculiar image implications, this exquisite fashion accessory will remain confined to being worn by a small minority of bow tie connoisseurs

fluid and blood, resulting in greater contamination of conventional ties than bow ties, as suggested in this study. Greater contamination does not, however, mean that the level of cross infection in patients attended must be higher. To confirm that, a much larger study looking at infection on postnatal wards would be necessary.

A necktie is the most useless item in any man's wardrobe. It does not offer any protection against the weather or injury; it is even rather uncomfortable. Yet most men would not dream of going to work or to any special event without wearing a tie, using it as their sole opportunity to flaunt their individuality, taste, and style against the dull uniform of a suit. ${ }^{9}$ Bow ties enjoyed a bad press through the 1970 s and 1980 s unless worn with formal evening clothes: American image consultant John Molloy warned that those wearing bow ties would not be taken seriously or be trusted with anything important. ${ }^{10}$ It is therefore not surprising that most doctors lack the courage and motivation to include a bow tie in their wardrobe, and none of the doctors in the study regularly wore bow ties. In view of this, and despite the fact that all the doctors interviewed said that they would consider wearing bow ties if they proved to be more hygienic, we believe that this exquisite fashion accessory will remain confined to a small minority of connoisseurs.

We thank the participants from Arrowe Park Hospital, Birmingham Maternity Hospital, Mill Road Maternity Hospital, the Royal Liverpool University Hospital in Liverpool, HM Stanley Hospital, and St Asaph and Whiston District General Hospital for their enthusiasm; Professor John Newton for his kind comments; and Schering Health Care for their generous sponsorship of this study.

1 Byrde P. The male image. The necktie. London: Anchor Press, 1979:111-23. 2 De Marly D. Working dress. A history of occupational clothing. Bath: Bath Press, 1986.

3 Bettman OL, Hench PS. A pictorial history of medicine. Springfield, IL: C C Thomas, 1976.

4 Margotta R. An illustrated history of medicine. Feltham: Hamlyn, 1967:229.

5 Sakula A. Portraits, paintings and sculptures. London: Royal Society of Medicine, 1988:150.

6 [Editorial]. Tailor and Cutter 1990: March 18:3.

7 Godlee R. Lister and his work. London: University of London Press, 1927: $100-2$.

Tooley S. Life of Florence Nightingale. London: S Bousfield, 1904:119.

9 Amies H. Introduction. In: Gibbons S. The Tie. London: Studio Editions, 1990:6.

10 Molloy JT. Dress for success. New York: Warner Books, 1976:76-8.

\title{
Is Friday the 13th bad for your health?
}

\author{
T J Scanlon, Robert N Luben, F L Scanlon, Nicola Singleton
}

Abstract

Objective-To examine the relation between health, behaviour, and superstition surrounding Friday 13th in the United Kingdom.

Design-Retrospective study of paired data comparing driving and shopping patterns and accidents.

Subjects-Drivers, shoppers, and residents.

Setting-South West Thames region.

Main outcome measures-Numbers of vehicles on motorways; numbers of shoppers in supermarkets; and hospital admissions due to accidents.

Results-There were consistently and significantly fewer vehicles on the southern section of the M25 on Friday the 13th compared with Friday the 6th. The numbers of shoppers were not significantly different on the two days. Admissions due to transport accidents were significantly increased on Friday 13th (total $65 v 45 ; p<0 \cdot 05$ ).

Conclusions-Friday 13th is unlucky for some. The risk of hospital admission as a result of a transport accident may be increased by as much as $52 \%$. Staying at home is recommended.

\section{Introduction}

Superstitions affect behaviour in all cultures in all parts of the world in some form or other. Most work, however, seems to have focused on the effects of supernatural beliefs in developing countries. ${ }^{1-6}$ Perhaps there is a subconscious perception that people in the West are too sophisticated to be influenced by such trifles.
The purpose of this study was to examine the relation between health, behaviour, and superstition in the United Kingdom. To assess this, we considered the relation between accidents and Friday the 13th, which is popularly perceived to be an unlucky day.

The origins of Friday the 13th as an unlucky day are twofold: Friday and the number 13 .

\section{FRIDAY}

Now Friday came, you old wives say,

Of all the week's the unluckiest day.

The roots of Friday as an unlucky day are predominantly Christian, Good Friday being the day on which Christ was crucified. Superstitions about Friday exist in various parts of the world. Within Britain itself there are regional superstitions. ${ }^{7}$ In Somerset, whoever turns a bed on Friday turns ships at sea. In Cumberland, babies born on a Friday were laid on the family Bible. In various regions, to call a doctor for the first time on a Friday is held to be a certain omen of death for the patient. (Unfortunately the GMC is unlikely to view this as sufficient good reason for refusing a house call.) Hair and nails should never be cut on a Friday.

Why these have been chosen as unlucky if occurring on a Friday is not clear. Other superstitions around Friday have more apparent origins. For example, laundry should never be washed on a Friday. A Yorkshire legend has it that as Christ was walking to Calvary a woman washing outside her house derisively waved a wet garment at his face, whereupon he cursed her and all who should in future wash on that day. Although generally considered unlucky for weddings,
Correspondence to: Dr Scanlon. 